\title{
Intentional price wars on the equilibrium path
}

Citation for published version (APA):

Pot, E. A., Peeters, R. J. A. P., Peters, H. J. M., \& Vermeulen, A. J. (2010). Intentional price wars on the equilibrium path. METEOR, Maastricht University School of Business and Economics. METEOR

Research Memorandum No. 028 https://doi.org/10.26481/umamet.2010028

Document status and date:

Published: 01/01/2010

DOI:

10.26481/umamet.2010028

Document Version:

Publisher's PDF, also known as Version of record

\section{Please check the document version of this publication:}

- A submitted manuscript is the version of the article upon submission and before peer-review. There can be important differences between the submitted version and the official published version of record.

People interested in the research are advised to contact the author for the final version of the publication, or visit the DOI to the publisher's website.

- The final author version and the galley proof are versions of the publication after peer review.

- The final published version features the final layout of the paper including the volume, issue and page numbers.

Link to publication

\footnotetext{
General rights rights.

- You may freely distribute the URL identifying the publication in the public portal. please follow below link for the End User Agreement:

www.umlib.nl/taverne-license

Take down policy

If you believe that this document breaches copyright please contact us at:

repository@maastrichtuniversity.nl

providing details and we will investigate your claim.
}

Copyright and moral rights for the publications made accessible in the public portal are retained by the authors and/or other copyright owners and it is a condition of accessing publications that users recognise and abide by the legal requirements associated with these

- Users may download and print one copy of any publication from the public portal for the purpose of private study or research.

- You may not further distribute the material or use it for any profit-making activity or commercial gain

If the publication is distributed under the terms of Article $25 \mathrm{fa}$ of the Dutch Copyright Act, indicated by the "Taverne" license above, 


\section{Maastricht University}

Erik Pot, Ronald Peeters, Hans Peters, Dries Vermeulen

Intentional Price Wars on the Equilibrium Path

$\mathrm{RM} / 10 / 028$

\section{METEOR}

Maastricht University School of Business and Economics

Maastricht Research School of Economics

of Technology and Organization

\section{P.O. Box 616}

NL - 6200 MD Maastricht

The Netherlands 


\title{
Intentional Price Wars on the Equilibrium Path
}

\author{
Erik Pot ${ }^{1}$, Ronald Peeters ${ }^{2}$, Hans Peters ${ }^{3}$ and Dries Vermeulen ${ }^{4}$
}

\begin{abstract}
In this paper we study the effect of information on the occurrence of intentional price wars on the equilibrium path. An episode of low prices is an intentional price war if it follows a period of high prices which was ended intentionally by one of the firms in the market (the price war leader). We show that for intentional price wars to exist on the equilibrium path, two elements are necessary regarding the information on which the firms base their decisions: (1) interperiod dynamics and (2) informational asymmetries. We illustrate this by means of a repeated price-setting game in which market shares fluctuate. Firms learn about the market share realizations at the beginning of each period. We show that intentional price wars on the equilibrium path are possible when firms have private information about their market share. When market shares are public information, we either see collusive price adjustment or episodes of low prices that do not classify as an intentional price war.
\end{abstract}

Keywords and Phrases: Price wars, repeated games, private information.

JEL Classification Numbers: C73, D43, L13.

\footnotetext{
${ }^{1}$ Department of Quantitative Economics, Maastricht University. Corresponding author at P.O. Box 616, 6200 MD Maastricht, The Netherlands. Email: e.pot@maastrichtuniversity.nl

${ }^{2}$ Department of Economics, Maastricht University.

${ }^{3}$ Department of Quantitative Economics, Maastricht University.

${ }^{4}$ Department of Quantitative Economics, Maastricht University.
} 


\section{Introduction}

A price war is one of the most extreme outcomes of price competition between oligopolists. Price wars are known to lead to erosion of revenues, profits, loss of innovative capabilities and even the collapse of entire industries (Rao, Bergen \& Davis 2000). Equilibrium explanations provided by theoretical models have focused on fluctuations in market demand or, more generally, shocks to market characteristics. ${ }^{1}$ However, many price wars that can be observed in real life cannot be explained by symmetric models, as they are deliberately initiated by one particular firm, the price war leader. In this paper, we therefore analyze such intentional price wars. An episode of low prices classifies as an intentional price war if it follows a period of high prices which was ended intentionally by one of the firms in the market (the price war leader). To provide a rational explanation for why this type of price war is observed, we show that for intentional price wars to exist on the equilibrium path, two elements are essential in the information on which firms base their decisions: (1) interperiod fluctuations and (2) asymmetries. We illustrate this by means of a model in which price wars of this type occur with certainty on the equilibrium path.

A price war is, as the name already suggests, a period of conflict, potentially leading to disastrous effects to firms and industries as a whole. Although it is arguably possible that parties in conflict are thrown into a price war without their consent, in reality we can observe price wars that were deliberately initiated by one of the firms in the market. The next examples show that intentional price wars take place and can have severe effects.

In 1992, a fierce price war on bus services between New York City and Washington DC was initiated by Peter Pan Trailways, after acquiring a Washington DC terminal. ${ }^{2}$ Peter Pan lowered their initial fare of $\$ 25$ to $\$ 9.95$, to "turn some heads". Their main rival, Greyhound, responded by cutting their fare to $\$ 7$, after which Peter Pan lowered their fare to $\$ 6.95$. Greyhound once more responded with a fare cut to $\$ 5$, which Peter Pan then matched, resulting in both firms operating below cost price.

In October 2003, Dutch multinational company Ahold decided to lower the prices of 1000 products in all branches of its supermarket chain Albert Heijn to regain its lost reputation and market share that it had suffered because of accounting scandals and other bad publicity the year before. Since this price drop was responded to by a similar lowering of prices by their competitors in the market, this marked the beginning of a price war which continued intensely

\footnotetext{
${ }^{1} C f$. Heil \& Helsen (2001) for an overview of theoretical and empirical literature on price wars.

${ }^{2}$ http://www.nytimes.com/1992/08/08/business/new-york-washington-5-is-cheaper-fare-since-1952 . html? pagewanted=1
} 
for a few years, resulting in a combined net loss of revenue of around $€ 18$ million a week at the end of November 2003. ${ }^{3}$ In April 2005, it was estimated that there had been a total loss of revenue in the Dutch food industry of $€ 1.7$ billion, of which half had directly influenced profits. ${ }^{4}$

More examples of intentional price wars in the airline industry are presented by Busse (2002), who empirically analyzes the question whether a firm is likely to intentionally start a price war because of its financial situation. Busse finds that the firm's individual situation plays an important role in its decision to intentionally start a price war, in line with industry insiders, who "identify the financial troubles of an individual carrier as an important motivation in initiating the fare cuts that trigger price wars". Busse mentions that this aspect is often ignored by existing models of oligopolistic competition that provide explanations for price wars.

Existing theoretical literature that explains the emergence of price wars usually analyzes a variation on the oligopoly model introduced by Friedman (1971). Firms repeatedly face a trade-off between collusive or aggressive behavior. Undercutting colluding opponents gives the deviator an immediate profit increase. However, this is followed by a punishment by the rivals in the form of pricing according to the one-shot game Nash equilibrium, which decreases long-run profits, relative to the collusive situation.

Realizing that a shock to the system is necessary to make firms switch from a high price to a low price regime, more elaborate models were developed in which firms face changing circumstances due to, for example, fluctuating market demand. In a branch of literature started by Green \& Porter (1984), firms cannot directly observe their opponents' behavior. A drop in one's own performance may be interpreted as being caused by a secret deviation from collusive behavior by one of the opponents, even though it also might be caused by a decrease in market demand. On the equilibrium path, price wars only occur because of decreased market demand and never as a result of a deviation. The second category of literature focuses on price wars in periods when market demand is such that deviation is most profitable: during booms. Rotemberg \& Saloner (1986) show that when market demand is high, prices go down to counterbalance the increased incentive to deviate. ${ }^{5}$ Another type of variation is to introduce capacity setting or capacity constraints. An important contribution of this type is Staiger \& Wolak (1992), who introduce a capacity-setting stage at the beginning of each period in a model based on that of

\footnotetext{
${ }^{3}$ http://www.rtl.nl/(/financien/rtlz/nieuws/)/components/financien/rtlz/2003/11_november/ 25-supermarkt_omzet_lager.xml

${ }^{4}$ http://www.elsevier.nl/web/Nieuws/Economie/29348/Duizenden-banen-weg-door-prijzenoorlog.htm

${ }^{5}$ The model was later extended in various ways (see for instance Kandori (1991), Haltiwanger \& Harrington (1991) and Bagwell \& Staiger (1997)).
} 
Rotemberg \& Saloner. This paper shows that when demand is low, and capacity is unused, a price war is most likely. ${ }^{6}$ These papers have all contributed to a better understanding of the dilemmas faced by firms when deciding to price high or low. However, because of their symmetric nature, they cannot predict which firm is likely to deviate (first) in equilibrium strategies. In equilibrium, firms either deviate jointly and simultaneously, or no firm deviates at all.

We can characterize an oligopolistic situation by the incentive situation the firms face, which is represented by the information a firm possesses at the moment decisions have to be made. In Friedman's model, information never changes. If firms repeatedly face the same situation, their decision will always be the same: they either collude or not, as deviation will either always be found profitable or never be found profitable. No price war will thus be possible on the equilibrium path, as there will never be a switch from periods with high prices to periods with lower prices. In order for such distinct episodes of high and low prices to occur, we may introduce shocks to the information firms receive. It is then possible that there are periods in which firms find it in their best interest to collude and later periods in which at least one of the firms finds it optimal to deviate. This change in the firms' information situation is what causes price wars on the equilibrium path. If a firm's information is such that it induces a decision to deviate from collusion, this firm is a candidate to be price war leader. However, if all firms face the same - albeit fluctuating - information (i.e., information is symmetric), intentional price wars on the equilibrium path are still unlikely. If firms receive the same information as all the other firms, they could predict whether there exists a firm that on the basis of that information prefers to deviate. If this is the case, the others can jointly reduce the incentive to deviate by decreasing the collusive price. We would thus observe adaptive pricing like in Rotemberg \& Saloner. If such an adaptation is impossible, we would see a simultaneous deviation by all firms in the market (if you know a firm will undercut, it is better to undercut yourself), which implies that no price war leader is present. However, if firms do not observe whether or not one of their rivals has an incentive to deviate (i.e., information is asymmetric), they cannot jointly adapt their strategies to it and it would be impossible to prevent a price war which is started by a firm that, on the basis of its private information, prefers to undercut. Thus, for a model to be able to explain intentional price wars in equilibrium, firms need to have fluctuating asymmetric

\footnotetext{
${ }^{6}$ While the above strands of literature focus on the impact of changing market conditions, an important contribution by Athey, Bagwell \& Sanchirico (2004) investigates the impact of private cost shocks on the stability of collusion. Their focus is on collusive, rigid pricing schemes and not explicitly on the possibility of a price war on the equilibrium path. However, their model does satisfy the conditions under which intentional price wars could be found in equilibrium strategies.
} 
information. We present a model that includes such features, and show that in such a model intentional price wars can occur in equilibrium.

\section{Model}

The model is based on Pot, Peeters, Peters \& Vermeulen (2009). Changing information comes in the form of fluctuating market shares. The level of information firms have depends on whether they are able to observe all realized market shares or only their own, before making their respective decisions. This way, we are able to study the effects of symmetric and asymmetric fluctuating information.

\subsection{The one shot game}

In our model, $n$ firms compete on price. To keep things tractable, we focus on the three relevant types of actions, namely collude $(C)$, undercut $(U)$, or price at marginal cost $(M)$. Thus, firms simultaneously choose an action $a_{i} \in\{C, M, U\}$. When firms divide the market, a vector $\varphi=\left(\varphi_{1}, \ldots, \varphi_{n}\right)$ of market shares denotes the market share distribution, where $\varphi_{i} \geq 0$ represents the market share of firm $i$. Market shares divide the total market, so $\sum_{i} \varphi_{i}=1$ and we assume that each $\varphi_{t}=\left(\varphi_{1 t}, \varphi_{2 t}, \cdots, \varphi_{n t}\right)$ is drawn from a uniform and i.i.d. distribution. This implies that tomorrow's market share division is independent of today's.

Given the action profile $a=\left(a_{i}\right)_{i \in N}$, each firm $i$ 's profit is denoted by $\Pi_{i}(a)$. By $\Pi$, we denote the highest attainable (monopoly) profit in the market. When $a_{i}=C$ for all $i$, then $\Pi_{i}(a)=\varphi_{i} \Pi$, as the firms divide this monopoly profit according to their market shares. For simplicity, we assume that undercutting is only profitable when it is done unilaterally. Thus, when there is a firm $k$ with $a_{k}=U$ and $a_{i}=C$ for all $i \neq k$, then $\Pi_{k}(a)=\Pi$ and $\Pi_{i}(a)=0$ for all $i \neq k$. In all other cases all profits are zero.

\subsection{The repeated game}

We are primarily interested in the occurrence of (intentional) price wars when firms repeat this one-shot game infinitely often. The timing in each period is modeled as follows. At the start of each period $t=0,1,2, \ldots$ the vector $\varphi_{t}=\left(\varphi_{1 t}, \ldots, \varphi_{n t}\right)$ of market shares is determined. Next, each firm receives information $h_{i t}$, which includes all realized market shares and all actions taken in all periods, and either a firm's own market share in the current period (private information), or all realized market shares in the current period (public information). At the beginning of the game, the initial division of market shares is given by $\varphi_{0}=\left(\varphi_{10}, \ldots, \varphi_{n 0}\right)$ and the associated 
information to the firms is denoted by $h_{0}=\left(h_{10}, \ldots, h_{n 0}\right)$.

We write $s\left(h_{t}\right)=\left(s_{1}\left(h_{1 t}\right), \ldots, s_{n}\left(h_{n t}\right)\right)$ for the profile of actions that is played at time $t$ given

the information $h_{t}=\left(h_{1 t}, \ldots, h_{n t}\right)$. Let $s^{t}$ denote the map $h_{t} \mapsto s\left(h_{t}\right)$. By $\mathbb{E}\left(\Pi_{i}\left(s^{t}\right) \mid h_{i 0}\right)$ we denote the expected value of the profit to firm $i$ at time $t$, given the strategy profile $s$ and the initial information $h_{i 0}$ of firm $i$.

Analogously, let $\mathbb{E}\left(\Pi_{i}\left(s^{t+k}\right) \mid h_{i t}\right)$ denote the expected value of the profit of firm $i$ at time $t+k$, given the strategy profile $s$ and information $h_{i t}$ to firm $i$ at time $t$. Write

$$
\Pi_{i}\left(s \mid h_{i t}\right)=\sum_{k=0}^{\infty} \delta^{k} \cdot \mathbb{E}\left(\Pi_{i}\left(s^{t+k}\right) \mid h_{i t}\right)
$$

for the present value of the stream of profits to firm $i$ at information set $h_{i t}$. A strategy profile $s$ is a perfect Bayesian Nash equilibrium when, at every information set $h_{i t}$,

$$
\Pi_{i}\left(s \mid h_{i t}\right) \geq \Pi_{i}\left(\left(s, s_{i}^{\prime}\right) \mid h_{i t}\right)
$$

holds for every strategy $s_{i}^{\prime}$ of firm $i$.

\subsection{Incentives and strategies}

The model presented above incorporates changing information which influences the incentives to collude or deviate. Clearly, these fluctuations can have an effect on the firms' behavior. Suppose the firms are in a collusive phase, but the realized market share division results in a very low level of demand for one of the firms in the market. That firm does not benefit much from collusion in that period as it will get only a small share of the total collusive profit. However, by undercutting the firm can try to capture the entire market. Compared to a situation in which market shares are symmetric, the firm thus has more to gain from successful undercutting of the rivals' collusive price. In other words, the changing individual situation causes that sometimes collusion is no longer rewarding enough for the firms to continue.

Since we are looking for intentional price wars on the equilibrium path, we need to define what type of strategy in our game corresponds to the definition of an intentional price wars we provided. Since a price war leader should be identifiable, the individual fluctuations should be critical in determining whether a firm starts a price war or not. In this model, these individual fluctuations are related to the market share, and as we have argued, if the market share is low, it is relatively more profitable to deviate. A sensible strategy should therefore prescribe to collude as long as firms receive information that their individual demand (market share) is high, and to deviate (start a price war) when individual demand is sufficiently low. Thus, a 
strategy giving rise to intentional price wars is essentially quasi-collusive and should look as follows:

Definition 2.1 Let $\widetilde{\varphi} \leq \frac{1}{n}$. The quasi-collusive strategy $Q_{i}$ (with threshold level $\widetilde{\varphi}$ ) of firm $i$ is defined by

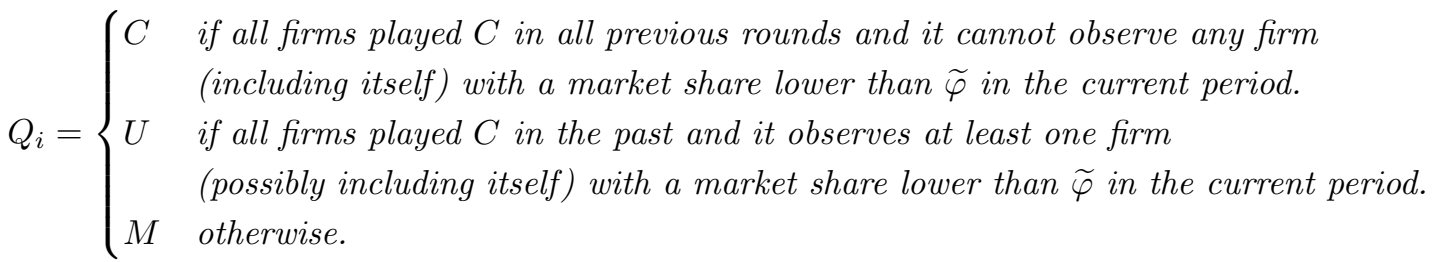

In this definition, we denote by $\tilde{\varphi}$ the minimum market share (endogenous to the strategy) at which a firm is still willing to continue collusion. We write $Q=\left(Q_{i}\right)_{i \in N}$ for the profile of quasi-collusive strategies. $^{7}$

\section{Results}

In this section, we present results on when the profile of quasi-collusive strategies constitutes a perfect Bayesian Nash equilibrium. In particular, we investigate when these strategies give rise to (intentional) price wars in this model. To illustrate the importance of information, we first look at the situation where the information a firm receives at the beginning of each period includes all firms' market share realizations (public information). This situation resembles existing literature on price wars in its results. We demonstrate the link with the results from Green \& Porter (1984), Rotemberg \& Saloner (1986) and Staiger \& Wolak (1992). Subsequently, we show what happens when firms can only observe their own market share (private information) and we find that intentional price wars on the equilibrium path are possible. All proofs can be found in section 5 .

\subsection{Market shares are public information}

First we analyze the case in which firms learn the entire realization of $\varphi_{t}$ at the beginning of period $t$. That is, $\varphi_{t}$ is included in $h_{i t}$ for all $i$ and $t$.

We would like to know if and when quasi-collusive strategy profile $Q$ is a perfect Bayesian Nash equilibrium. The next theorem shows the result.

\footnotetext{
${ }^{7}$ Assuming that the punishment phase lasts a finite number $T$ periods would only quantitatively change our results.
} 
Theorem 3.1 The strategy profile $Q$ is a perfect Bayesian Nash equilibrium if and only if

$$
\widetilde{\varphi}+\frac{\delta(1-n \widetilde{\varphi})^{n-1}}{1-\delta(1-n \widetilde{\varphi})^{n-1}} \cdot \frac{1}{n} \geq 1 .
$$

The following corollary states for which discount factors there exists a strategy profile $Q$ that forms a perfect Bayesian Nash equilibrium.

Corollary 3.2 When $\delta<\frac{n}{n+1}$, there exists no $\widetilde{\varphi} \leq \frac{1}{n}$ for which the strategy profile $Q$ forms a perfect Bayesian Nash equilibrium. When $\delta=\frac{n}{n+1}, Q$ forms a perfect Bayesian Nash equilibrium precisely when $\widetilde{\varphi}=0$. When $\delta>\frac{n}{n+1}$, there exists a $\varphi^{*} \in\left[0, \frac{1}{n}\right]$, which is increasing in $\delta$, such that $Q$ forms a perfect Bayesian Nash equilibrium precisely when $\widetilde{\varphi} \in\left[0, \varphi^{*}\right]$.

This corollary shows that when the discount factor is sufficiently high, strategy profile $Q$ can be a perfect Bayesian Nash equilibrium. The minimum level of the market share at which firms still collude is bounded from above by a maximum level $\varphi^{*}$ which depends on the discount factor and from below by 0 . High prices will be visible as long as the market share realization is such that each firm has a market share above $\widetilde{\varphi}$. As soon as a realization occurs where this is no longer the case, however, all firms will observe this and, knowing that deviation is unavoidable, deviate themselves. This will occur with probability 1 in our model in the long run and causes prices to break down to marginal cost level.

These unavoidable episodes of low prices are no intentional price wars. Although they follow a period of high prices, they do not satisfy the criterion that a price war leader can be identified. They should therefore be seen as breakdowns of collusion similar to the price wars in Green \& Porter (1984) and Staiger \& Wolak (1992).

Furthermore, we know already from Pot, Peeters, Peters \& Vermeulen (2009) that if firms have perfect information about the market shares of their opponents at the beginning of each period, an adaptive collusive strategy can also be an option. Such a strategy "adapts" the collusive price to the incentive situation of the worst-off firm, making it unprofitable to undercut. This type of strategy is comparable to the one we see in Rotemberg \& Saloner (1986) and gives rise to periods of slightly lower prices, not classifiable as intentional price wars.

\subsection{Market shares are private information}

We now turn to the case in which firms only observe their own market share at the beginning of the period. Formally, $\varphi_{i t}$ is part of $h_{i t}$ for all $i \in N$, but the vector $\varphi_{t}$ in its entirety is not. We show that the quasi-collusive strategy profile can be a perfect Bayesian Nash equilibrium. 
Because firms cannot observe their opponents' situations, this strategy profile gives rise to intentional price wars on the equilibrium path, as unilateral deviations then occur at some moment with certainty.

The next theorem indicates precisely when $Q$ constitutes a perfect Bayesian Nash equilibrium.

Theorem 3.3 If $\widetilde{\varphi}>0$, the strategy profile $Q$ is a perfect Bayesian Nash equilibrium precisely when

$$
\widetilde{\varphi}+\delta \cdot \frac{n \cdot(1-(n-1) \widetilde{\varphi})^{n-1}-(n-1) \cdot(1-n \widetilde{\varphi})^{n-1}}{n \cdot\left(1-\delta \cdot(1-n \widetilde{\varphi})^{n-1}\right)}=1 .
$$

If $\widetilde{\varphi}=0, Q$ is a perfect Bayesian Nash equilibrium precisely when $\delta \geq \frac{n}{n+1}$.

The following corollary states for which discount factors there exists a strategy profile $Q$ that forms a perfect Bayesian Nash equilibrium.

Corollary 3.4 When $\delta<\frac{n}{n+1}$, there exists no $\widetilde{\varphi}$ for which the quasi-collusive strategy profile $Q$ forms a perfect Bayesian Nash equilibrium. When $\delta=\frac{n}{n+1}, Q$ forms a perfect Bayesian Nash equilibrium precisely when $\widetilde{\varphi}=0$. When $\delta>\frac{n}{n+1}$, there are precisely two values of $\widetilde{\varphi}$ for which $Q$ forms a perfect Bayesian Nash equilibrium, namely $\widetilde{\varphi}=0$, and a unique solution $0<\widetilde{\varphi}<\frac{1}{n(n-1)}$ to the equation

$$
\varphi+\delta \cdot \frac{n \cdot(1-(n-1) \varphi)^{n-1}-(n-1) \cdot(1-n \varphi)^{n-1}}{n \cdot\left(1-\delta \cdot(1-n \varphi)^{n-1}\right)}=1
$$

This corollary shows that when the discount factor is sufficiently high, strategy profile $Q$ can be a perfect Bayesian Nash equilibrium, also when firms have private information. There are two types of equilibrium in quasi-collusive strategies. First, the threshold level below which firms deviate can be 0 . In this case, deviation never takes place and this strategy can essentially be seen as fully collusive. Second, the minimum level of the market share at which firms still collude can be strictly positive. High prices will be visible as long as the market share realization is such that each firm has a market share above $\widetilde{\varphi}$. However, as soon as a realization occurs where this is no longer the case, the firm which market share is lower than the threshold level deviates. This will occur with probability 1 in our model in the long run. Furthermore, as it cannot be observed by the rivals that the firm is in this position, it cannot be prevented.

The intuition why there are only two threshold levels that are possible in a perfect Bayesian Nash equilibrium (instead of the range of threshold levels when market shares are public information) is that when a firm has a market share below the threshold level which is unobservable to the 
other firms, the firm has the option to continue collusive play. The lower the threshold market share is, the larger the probability that the firm is the only one with a market share below the threshold level. Continuing collusion will then be more attractive. This creates an additional constraint to the equilibrium strategy and payoff.

The realization of events when firms follow the quasi-collusive strategy profile $Q$ with threshold $\widetilde{\varphi}$ as in Corollary 3.4 is an example of an intentional price war. Low prices follow a period of high prices, as aggressive pricing only occurs when there is a market share realization which renders a sufficiently low market share for at least one of the firms. A price war leader can be identified, as undercutting will only be done by a firm with a sufficiently low market share. Moreover, undercutting is done to increase profits, as the strategy is part of a perfect Bayesian Nash equilibrium. As one can see from the strategy, both the fluctuating information on market shares and the fact that this information is private play a critical role in facilitating this type of price wars.

\section{Concluding remarks}

We argued that fluctuations and asymmetries in the firms' information are critical elements if we try to explain intentional price wars. The model we presented and its results support this. Note, however, that the way we chose to model asymmetric fluctuations in information is not the only possibility to represent such a situation. Another possibility is that the market characteristics are stable, but that firms in each period receive different (possibly false) signals about these characteristics.

We have argued that the information a firm possesses represents the decision problem a firm faces. There are various factors, both inside and outside of the firm's control, that influence the position of the firm. Reputation effects, changing loyalties or random behavior on part of the consumers could change the outcome of competition even though prices remain constant. Information the firm receives about these factors might therefore change over time and this could gradually or drastically change the firm's preferred course of action.

If we look at one of the examples of an intentional price war mentioned in the introduction, the Dutch supermarket price war, the price war leader suffered from a decreasing market share because of reputational problems. In press statements this was also indicated by the firm as the main reason for its aggressive pricing. Also in the New York - Washington fare war, a change in the individual situation seems to have triggered the price war. Acquiring the new terminal changed Peter Pan Trailways' individual situation in such a way that it deemed a price war 
more profitable than (continued) collusion. Finally, our results confirm the conclusion made in Busse (2002) that firms in an adverse individual (financial) situation are more likely to start a price war. In our model, this is represented by the bad collusive payoff resulting from a low realized market share. To look at changes in the individual information situation thus seems appropriate when trying to explain intentional price wars.

We also show that this information should be asymmetric. If all firms would receive the same information, rival firms would either be able to decrease incentives to deviate or they would deviate en masse themselves. The condition of private, asymmetric information seems natural in real life. For any firm it can be argued that it might have a general idea about the situation its competitors face, but to always be able to determine whether it is in the best interest of the rival to continue collusion or to deviate seems unlikely. Especially regarding issues of financial stability, it seems hard to exactly determine the position of all rival firms without being able to see their (financial) accounts. It could be argued, though, that if firms have to make guesses about their competitors' situations, mutual distrust might cause firms to deviate even sooner than predicted in our model.

The results show a clear connection between collusion and price wars. Even though these two outcomes of price competition seem to be complete opposites, it is clear that in Bertrandtype models of oligopolistic competition the two phenomena are necessarily linked to enable the possibility of a switch between a period of high prices and one of low prices, the typical characteristic of a price war. ${ }^{8}$ However, our results show a more subtle connection. A price war does not necessarily occur if collusion is not sustainable (at all). Instead, the possibility of intentional price wars actually depends on the prerequisite that the firms' discount factor is sufficiently high to sustain collusion. This is something which might be counterintuitive as high discount factors are usually associated with persisting high prices as a consequence of collusion. These results show that if we allow for a sensible element of selfishness to the usual trigger strategy (making the strategy essentially quasi-collusive), we find that when the discount factor is high, equilibria are possible in which with certainty an intentional price war occurs at some point. This questions the need for intervention in such markets.

\footnotetext{
${ }^{8}$ For a model in which high and low prices occur naturally in competition, see Pot, Flesch, Peeters \& Vermeulen (2009).
} 


\section{Proofs}

Before we present the proofs of the theorems and corollaries from the text, we derive three lemmas.

We first compute the probability of a market share realization such that no firm prefers undercutting to colluding.

Lemma 5.1 The probability that all firms have at least a market share of $\widetilde{\varphi} \leq \frac{1}{n}$ is equal to

$$
P^{+} \equiv \mathbb{P}\left[\varphi_{i t} \geq \widetilde{\varphi}, \forall i \in N\right]=(1-n \widetilde{\varphi})^{n-1}
$$

\section{Proof.}

Consider a standard $(n-1)$-dimensional simplex with vertices

$$
(1,0, \ldots, 0) ;(0,1, \ldots, 0) ; \ldots ;(0,0, \ldots, 1)
$$

This simplex represents all possible market share realizations. The barycenter of this simplex is $\left(\frac{1}{n}, \frac{1}{n}, \ldots, \frac{1}{n}\right)$. The distance from the barycenter to a vertex equals

$$
\sqrt{(n-1)\left(\frac{1}{n}\right)^{2}+\left(\frac{1-n}{n}\right)^{2}}=\sqrt{\frac{n-1}{n}} .
$$

Now consider the $(n-1)$-dimensional simplex with vertices

$$
(1-(n-1) \widetilde{\varphi}, \widetilde{\varphi}, \ldots, \widetilde{\varphi}) ;(\widetilde{\varphi}, 1-(n-1) \widetilde{\varphi}, \ldots, \widetilde{\varphi}) ; \ldots ;(\widetilde{\varphi}, \widetilde{\varphi}, \ldots, 1-(n-1) \widetilde{\varphi})
$$

This simplex represents all possible market share realizations in which each firm has at least a market share of $\widetilde{\varphi}$ and has the barycenter at $\left(\frac{1}{n}, \frac{1}{n}, \ldots, \frac{1}{n}\right)$ as well. The distance from the barycenter to a vertex of this simplex is

$$
\sqrt{(n-1)\left(\frac{1}{n}-\widetilde{\varphi}\right)^{2}+\left(\frac{1}{n}-(1-(n-1) \widetilde{\varphi})\right)^{2}}=(1-n \widetilde{\varphi}) \sqrt{\frac{n-1}{n}} .
$$

As the simplex has $(n-1)$ dimensions, the volume of the second simplex is $(1-n \widetilde{\varphi})^{n-1}$ times the volume of the first one.

We write $P_{i t}$ for the probability that $\varphi_{j t} \geq \widetilde{\varphi}$ for all $j \neq i$ given $\varphi_{i t}$. The following lemma specifies $P_{i t}$ for general $\varphi_{i t}$ and $\widetilde{\varphi}$.

Lemma 5.2 Suppose that $\varphi_{i t} \leq \widehat{\varphi}$. Then, given $\varphi_{i t}$,

$$
P_{i t}=\left(1-\frac{(n-1) \widetilde{\varphi}}{1-\varphi_{i t}}\right)^{n-2} .
$$




\section{Proof.}

Consider an $(n-1)$-dimensional simplex with vertices

$$
\left(\varphi_{i t}, 1-\varphi_{i t}, 0, \ldots, 0\right) ;\left(\varphi_{i t}, 0,1-\varphi_{i t}, \ldots, 0\right) ; \ldots ;\left(\varphi_{i t}, 0,0, \ldots, 1-\varphi_{i t}\right) .
$$

This simplex represents all possible market share realizations in which the first firm has a market share of $\varphi_{i t}$. The barycenter of this simplex is $\left(\varphi_{i t}, \frac{1-\varphi_{i t}}{n-1}, \ldots, \frac{1-\varphi_{i t}}{n-1}\right)$. The distance from the barycenter to a vertex is

$$
\sqrt{(n-2)\left(\frac{1-\varphi_{i t}}{n-1}\right)^{2}+\left(\frac{1-\varphi_{i t}}{n-1}-\left(1-\varphi_{i t}\right)\right)^{2}}=\sqrt{\frac{(n-2)\left(\varphi_{i t}-1\right)^{2}}{n-1}} .
$$

Now consider the $(n-1)$-dimensional simplex with vertices

$$
\left(\varphi_{i t}, 1-\varphi_{i t}-(n-2) \widetilde{\varphi}, \widetilde{\varphi}, \ldots, \widetilde{\varphi}\right) ; \ldots \ldots ;\left(\varphi_{i t}, \widetilde{\varphi}, \widetilde{\varphi}, \ldots, 1-\varphi_{i t}-(n-2) \widetilde{\varphi}\right)
$$

This simplex represents all possible market share realizations in which the first firm has market share $\varphi_{i t}$ and all other firms have at least a market share of $\widetilde{\varphi}$. The barycenter of this simplex is also at $\left(\varphi_{i t}, \frac{1-\varphi_{i t}}{n-1}, \ldots, \frac{1-\varphi_{i t}}{n-1}\right)$. Straightforward calculation shows that the distance from the barycenter to a vertex of this simplex is

$$
\left(1-\frac{(n-1) \widetilde{\varphi}}{1-\varphi_{i t}}\right) \sqrt{\frac{(n-2)\left(\varphi_{i t}-1\right)^{2}}{n-1}} .
$$

As the simplices differ in $(n-2)$ dimensions, the volume of the second simplex is $\left(1-\frac{(n-1) \widetilde{\varphi}}{1-\varphi_{i t}}\right)^{n-2}$ times the volume of the first one.

The next lemma shows the cumulative distribution of a firm's market share $\varphi_{i t}$.

Lemma 5.3 The cumulative distribution function of $\varphi_{i t}$ is

$$
F\left(\varphi_{i t}\right)=1-\left(1-\varphi_{i t}\right)^{n-1}
$$

\section{Proof.}

Consider the standard $(n-1)$-dimensional simplex with vertices

$$
(1,0, \ldots, 0) ;(0,1, \ldots, 0) ; \ldots ;(0,0, \ldots, 1)
$$

If we intersect this simplex by the halfspace $\varphi_{i} \geq \varphi^{*}$ we get a smaller simplex of dimension $(n-1)$. Multiplication by a factor of $\frac{1}{1-\varphi^{*}}$ using the $i^{\text {th }}$ unit vector as the origin transforms the smaller simplex into the larger one. Thus, because these simplices have $(n-1)$ dimensions, the volume of the second simplex is $\left(1-\varphi^{*}\right)^{n-1}$ times the first one. Hence, since the value $F\left(\varphi^{*}\right)$ 
of the cumulative distribution function evaluated at $\varphi_{i}=\varphi^{*}$ equals 1 minus the probability of the smaller simplex, we find that $F\left(\varphi_{i}\right)=1-\left(1-\varphi_{i t}\right)^{n-1}$.

\section{Proof of Theorem 3.1.}

Let $\Phi$ denote the set of market share realizations with $\varphi_{i} \geq \widetilde{\varphi}$ for all firms $i \in N$. Due to the one deviation property, the quasi-collusive strategy profile is a perfect Bayesian Nash equilibrium exactly when every firm $i$, at every time $t$, and at every information set $h_{i t}$ the quasi-collusive strategy yields at least the same expected payoff as an instantaneous deviation. Thus, consider firm $i$, at time $t$, at information set $h_{i t}$. Let $\mathbb{E}\left[Q \mid h_{i t}\right]$ denote the expected payoff of following the quasi-collusive strategy, and $\mathbb{E}\left[D \mid h_{i t}\right]$ the expected payoff of an instantaneous optimal deviation, both given market share vector $\varphi_{t}$ and given that the opponents play according to $Q$. We need to analyze two separate situations.

A. $\varphi_{t} \notin \Phi$. Given that the opponents play $M$ forever according to $Q$, firm $i$ will get an expected payoff of 0 , no matter what its strategy is. The equilibrium condition

$$
\mathbb{E}\left[Q \mid h_{i t}\right] \geq \mathbb{E}\left[D \mid h_{i t}\right]
$$

is therefore trivially satisfied in this case.

B. $\varphi_{t} \in \Phi$. Deviation from $Q$ will yield a one-period monopoly payoff after which profits will be equal to 0 . Therefore $\mathbb{E}\left[D \mid \varphi_{t} \in \Phi\right]=\Pi$. On the other hand the expected payoff of following $Q$ is equal to

$$
\begin{aligned}
\mathbb{E}\left[Q \mid \varphi_{t} \in \Phi\right]=\varphi_{i t} \Pi & +\delta \mathbb{P}\left[\varphi_{t+1} \notin \Phi\right] \cdot \mathbb{E}\left[Q \mid \varphi_{t+1} \notin \Phi\right] \\
& +\delta \mathbb{P}\left[\varphi_{t+1} \in \Phi\right] \cdot \mathbb{E}\left[Q \mid \varphi_{t+1} \in \Phi\right]
\end{aligned}
$$

According to Lemma 5.1, $\mathbb{P}\left[\varphi_{t+1} \in \Phi\right]=(1-n \widetilde{\varphi})^{n-1}$. Furthermore, $\mathbb{E}\left[Q \mid \varphi_{t+1} \notin \Phi\right]=0$. Since the expectation of future market shares and payoff is independent from the current situation, $\mathbb{E}\left[Q \mid \varphi_{t+k} \in \Phi\right]$ is constant for any $k \geq 1$ and equal to

$$
\frac{1}{n} \cdot \frac{\Pi}{1-\delta(1-n \widetilde{\varphi})^{n-1}}
$$

Substitution and rewriting yields

$$
\mathbb{E}\left[Q \mid \varphi_{t} \in \Phi\right]=\left(\varphi_{i t}+\frac{\delta(1-n \widetilde{\varphi})^{n-1}}{1-\delta(1-n \widetilde{\varphi})^{n-1}} \cdot \frac{1}{n}\right) \Pi
$$

The equilibrium condition $\mathbb{E}\left[Q \mid \varphi_{t} \in \Phi\right] \geq \mathbb{E}\left[D \mid \varphi_{t} \in \Phi\right]$ is thus satisfied when

$$
\left(\varphi_{i t}+\frac{\delta(1-n \widetilde{\varphi})^{n-1}}{1-\delta(1-n \widetilde{\varphi})^{n-1}} \cdot \frac{1}{n}\right) \geq 1 .
$$


Finally notice that the left-hand side of the above inequality is increasing in $\varphi_{i t}$. Since the condition should hold for all possible $\varphi_{i t}$ with $\varphi_{t} \in \Phi$, it suffices to require that the inequality holds for $\varphi_{i t}=\widetilde{\varphi}$.

\section{Proof of Corollary 3.2.}

Consider the function

$$
f(\varphi)=1-\frac{\delta(1-n \varphi)^{n-1}}{1-\delta(1-n \varphi)^{n-1}} \cdot \frac{1}{n}
$$

on the domain $\left[0, \frac{1}{n}\right]$. From Theorem 3.1 we know that $Q$ is an equilibrium precisely when $\widetilde{\varphi} \geq f(\widetilde{\varphi})$. We check when this condition is satisfied.

Since $f$ is strictly increasing and concave on its domain, and since $f\left(\frac{1}{n}\right)>\frac{1}{n}$, if $f(\widetilde{\varphi}) \geq \widetilde{\varphi}$, then $f(\varphi)>\varphi$ for all $\varphi \in\left(\widetilde{\varphi}, \frac{1}{n}\right]$. Thus, the set of $\varphi$ with $\varphi \geq f(\varphi)$ is of the form $\left[0, \varphi^{*}\right]$ (possibly empty) for some $\varphi^{*}$.

If $\delta<\frac{n}{n+1}$, then $f(0)>0$. Thus there are no $\varphi$ with $\varphi \geq f(\varphi)$.

If $\delta=\frac{n}{n+1}$, then $f(0)=0$, and $\varphi \geq f(\varphi)$ only holds for $\varphi=0$.

If $\delta>\frac{n}{n+1}$, then $f(0)<0$, and by the Intermediate Value Theorem there exists a point $\varphi^{*}$ with $f\left(\varphi^{*}\right)=\varphi^{*}$. Since $f$ is strictly increasing and concave, this point $\varphi^{*}$ is unique, and the set $\left[0, \varphi^{*}\right]$ is exactly the set of solutions $\varphi$ of the inequality $\varphi \geq f(\varphi)$.

\section{Proof of Theorem 3.3.}

We use the following notation. Let $\widehat{\varphi}=1-(n-1) \widetilde{\varphi}$. We write $P_{i t}$ for the probability that $\varphi_{j t} \geq \widetilde{\varphi}$ for all $j \neq i$ given $\varphi_{i t}$. Note that, when $\varphi_{i t}>\widehat{\varphi}$, we have at least one firm $j \neq i$ with $\varphi_{j t}<\tilde{\varphi}$. Hence, $P_{i t}=0$ in that case.

Due to the one deviation property, the quasi-collusive strategy profile is a perfect Bayesian Nash equilibrium exactly when every firm $i$, at every time $t$, and at every information set $h_{i t}$ the quasi-collusive strategy yields at least the same expected payoff as an instantaneous deviation. Thus, consider firm $i$, at time $t$, having a market share $\varphi_{i t}$. Let $\mathbb{E}\left[Q \mid \varphi_{i t}\right]$ denote the expected payoff of following the quasi-collusive strategy, and $\mathbb{E}\left[D \mid \varphi_{i t}\right]$ the expected payoff of an instantaneous optimal deviation, both given information set $h_{i t}$ and given that the opponents play according to $Q$. We analyze three separate situations, A, B and C.

A. $\varphi_{i t}>\widehat{\varphi}$. In this case, according to $Q$, there will be at least one opponent playing $U$ in the next period, after which $M$ will be played forever. Thus, firm $i$ will get an expected payoff of 0 , no matter what its strategy is. Hence in this case, $\mathbb{E}\left[Q \mid \varphi_{i t}\right]=0=\mathbb{E}\left[D \mid \varphi_{i t}\right]$, and the equilibrium condition $\mathbb{E}\left[Q \mid \varphi_{i t}\right] \geq \mathbb{E}\left[D \mid \varphi_{i t}\right]$ is trivially satisfied. 
Cases $\mathrm{B}$ and $\mathrm{C}$ require more attention. We start with deriving expressions for both expected payoffs $\mathbb{E}\left[D \mid \varphi_{i t}\right]$ and $\mathbb{E}\left[Q \mid \varphi_{i t}\right]$ for the these two cases.

B. $\widetilde{\varphi} \leq \varphi_{i t} \leq \widehat{\varphi}$. In this situation, deviation from $Q$ will yield a one-period payoff of $\Pi$, provided there is no firm with a market share less than $\widetilde{\varphi}$, after which the firm will receive a payoff of 0 infinitely. Thus we find that

$$
\mathbb{E}\left[D \mid \varphi_{i t}\right]=P_{i t} \cdot \Pi \text {. }
$$

Following $Q$ yields an expected payoff $\mathbb{E}\left[Q \mid \varphi_{i t}\right]$ equal to

$$
\begin{aligned}
P_{i t} \cdot \varphi_{i t} \cdot \Pi & +\delta \cdot P_{i t} \cdot \mathbb{P}\left[\varphi_{i t+1}<\widetilde{\varphi}\right] \cdot \mathbb{E}\left[Q \mid \varphi_{i t+1}<\widetilde{\varphi}\right] \\
& +\delta \cdot P_{i t} \cdot \mathbb{P}\left[\widetilde{\varphi} \leq \varphi_{i t+1} \leq \widehat{\varphi}\right] \cdot \mathbb{E}\left[Q \mid \widetilde{\varphi} \leq \varphi_{i t+1} \leq \widehat{\varphi}\right] .
\end{aligned}
$$

We write

$$
\mathbb{E}\left[Q \mid \varphi_{i t}\right]=P_{i t} \cdot\left(\varphi_{i t} \cdot \Pi+Y\right)
$$

with

$$
Y=\delta \cdot \mathbb{P}\left[\varphi_{i t+1}<\widetilde{\varphi}\right] \cdot \mathbb{E}\left[Q \mid \varphi_{i t+1}<\widetilde{\varphi}\right]+\delta \cdot \mathbb{P}\left[\widetilde{\varphi} \leq \varphi_{i t+1} \leq \widehat{\varphi}\right] \cdot \mathbb{E}\left[Q \mid \widetilde{\varphi} \leq \varphi_{i t+1} \leq \widehat{\varphi}\right]
$$

C. $\varphi_{i t}<\widetilde{\varphi}$. The optimal deviation from $Q$ in this case is playing $C$. Playing $C$ ensures continuation of collusion, provided no other firm plays $U$ in the next period. Therefore, using the same reasoning as above, we find that in this case

$$
\mathbb{E}\left[D \mid \varphi_{i t}\right]=P_{i t} \cdot\left(\varphi_{i t} \cdot \Pi+Y\right) .
$$

Following $Q$ in this case, and thereby attracting the entire market for one period unless there is also another deviator, yields, as it does for $\mathbb{E}\left[D \mid \varphi_{i t}\right]$ in case $\mathrm{A}$,

$$
\mathbb{E}\left[Q \mid \varphi_{i t}\right]=P_{i t} \cdot \Pi \text {. }
$$

We have derived expressions for $\mathbb{E}\left[D \mid \varphi_{i t}\right]$ and $\mathbb{E}\left[Q \mid \varphi_{i t}\right]$ for both cases. Notice that the expression $P_{i t} \cdot \Pi$ equals $\mathbb{E}\left[D \mid \varphi_{i t}\right]$ in case $\mathrm{B}$ and $\mathbb{E}\left[Q \mid \varphi_{i t}\right]$ in case $\mathrm{C}$. The expression $P_{i t}$. $\left(\varphi_{i t} \cdot \Pi+Y\right)$ equals $\mathbb{E}\left[D \mid \varphi_{i t}\right]$ in case $\mathrm{C}$ and $\mathbb{E}\left[Q \mid \varphi_{i t}\right]$ in case $\mathrm{B}$. Thus, we get two conditions: $\varphi_{i t} \cdot \Pi+Y \geq \Pi$ when $\widetilde{\varphi} \leq \varphi_{i t} \leq \widehat{\varphi}$, and $\varphi_{i t} \cdot \Pi+Y \leq \Pi$ when $\varphi_{i t}<\widetilde{\varphi}$.

$\Pi$ is a constant, while $\varphi_{i t} \cdot \Pi+Y$ is linearly increasing in $\varphi_{i t}$. Therefore, since $P_{i t}$ is non-negative and continuous in $\varphi_{i t}$, we can deduce that the equilibrium condition

$$
\mathbb{E}\left[Q \mid \varphi_{i t}\right] \geq \mathbb{E}\left[D \mid \varphi_{i t}\right] \quad \text { for all } \varphi_{i t}
$$


is equivalent to the requirement that

$$
\mathbb{E}\left[Q \mid \varphi_{i t}=\widetilde{\varphi}\right]=\mathbb{E}\left[D \mid \varphi_{i t}=\widetilde{\varphi}\right]
$$

This equality boils down to the equation

$$
\widetilde{\varphi} \cdot \Pi+Y=\Pi
$$

We compute $Y$ as follows. Write $V=\mathbb{E}\left[Q \mid \widetilde{\varphi} \leq \varphi_{i t} \leq \hat{\varphi}\right]$ and $P_{1}=\mathbb{P}\left[\widetilde{\varphi} \leq \varphi_{i t+1} \leq \hat{\varphi}\right]$. Then, since $\widehat{\varphi}=1-(n-1) \widetilde{\varphi}$,

$$
P_{1} \cdot V=\int_{\widetilde{\varphi}}^{1-(n-1) \tilde{\varphi}} \mathbb{E}\left[Q \mid \varphi_{i t}\right] \cdot F^{\prime}\left(\varphi_{i t}\right) d \varphi_{i t},
$$

where $\mathbb{E}\left[Q \mid \varphi_{i t}\right]$ is given by the expression in case $\mathrm{B}$, and

$$
F^{\prime}\left(\varphi_{i t}\right)=(n-1) \cdot\left(1-\varphi_{i t}\right)^{n-2}
$$

is the density of the cumulative probability distribution in Lemma 5.3. Using the formula from Lemma 5.2 for $P_{i t}$ we find that the integrand is

$$
\mathbb{E}\left[Q \mid \varphi_{i t}\right] \cdot F^{\prime}\left(\varphi_{i t}\right)=(n-1) \cdot\left(1-(n-1) \widetilde{\varphi}-\varphi_{i t}\right)^{n-2} \cdot\left(\varphi_{i t} \cdot \Pi+Y\right) .
$$

Thus, computing the integral, we find that

$$
P_{1} \cdot V=(1-n \widetilde{\varphi})^{n-1} \cdot\left(\frac{\Pi}{n}+Y\right) .
$$

We compute $Y$, using its definition in B. To do so, write $P_{2}=\mathbb{P}\left[\varphi_{i t+1}<\widetilde{\varphi}\right.$. Further, since $V$ does not depend on time, we can also write $V=\mathbb{E}\left[Q \mid \widetilde{\varphi} \leq \varphi_{i t+1} \leq \widehat{\varphi}\right]$. Using this notation, we have

$$
Y=\delta \cdot P_{2} \cdot \mathbb{E}\left[Q \mid \varphi_{i t+1}<\widetilde{\varphi}\right]+\delta \cdot P_{1} \cdot V
$$

Combining this with the above expression for $P_{1} \cdot V$ we find that

$$
Y=\delta \cdot P_{2} \cdot \mathbb{E}\left[Q \mid \varphi_{i t+1}<\widetilde{\varphi}\right]+\delta \cdot(1-n \widetilde{\varphi})^{n-1} \cdot\left(\frac{\Pi}{n}+Y\right) .
$$

Solving for $Y$ yields

$$
\left(1-\delta \cdot(1-n \widetilde{\varphi})^{n-1}\right) \cdot Y=\frac{\delta \cdot(1-n \widetilde{\varphi})^{n-1} \cdot \Pi}{n}+\delta \cdot P_{2} \cdot \mathbb{E}\left[Q \mid \varphi_{i t+1}<\widetilde{\varphi}\right] .
$$

Thus,

$$
Y=\delta \cdot \frac{(1-n \widetilde{\varphi})^{n-1} \cdot \Pi+n \cdot P_{2} \cdot \mathbb{E}\left[Q \mid \varphi_{i t+1}<\widetilde{\varphi}\right]}{n \cdot\left(1-\delta \cdot(1-n \widetilde{\varphi})^{n-1}\right)} .
$$


Now we compute that

$$
\begin{aligned}
P_{2} \cdot \mathbb{E}\left[Q \mid \varphi_{i t+1}<\widetilde{\varphi}\right] & =\int_{0}^{\widetilde{\varphi}} \mathbb{E}\left[Q \mid \varphi_{i t}\right] \cdot F^{\prime}\left(\varphi_{i t}\right) d \varphi_{i t} \\
& =\int_{0}^{\widetilde{\varphi}} P_{i t} \cdot \Pi \cdot(n-1) \cdot\left(1-\varphi_{i t}\right)^{n-2} d \varphi_{i t} \\
& =\int_{0}^{\widetilde{\varphi}}\left(1-\frac{(n-1) \widetilde{\varphi}}{1-\varphi_{i t}}\right)^{n-2} \cdot \Pi \cdot(n-1) \cdot\left(1-\varphi_{i t}\right)^{n-2} d \varphi_{i t} \\
& =\int_{0}^{\widetilde{\varphi}}(n-1) \cdot \Pi \cdot\left(1-(n-1) \widetilde{\varphi}-\varphi_{i t}\right)^{n-2} d \varphi_{i t} \\
& =\Pi \cdot\left((1-(n-1) \widetilde{\varphi})^{n-1}-(1-n \widetilde{\varphi})^{n-1}\right)
\end{aligned}
$$

Substituting and rewriting yields

$$
Y=\delta \cdot \Pi \cdot \frac{n \cdot(1-(n-1) \widetilde{\varphi})^{n-1}-(n-1) \cdot(1-n \widetilde{\varphi})^{n-1}}{n \cdot\left(1-\delta \cdot(1-n \widetilde{\varphi})^{n-1}\right)} .
$$

Substituting this expression for $Y$ into the equilibrium condition

$$
\widetilde{\varphi} \cdot \Pi+Y=\Pi
$$

yields

$$
\widetilde{\varphi}+\delta \cdot \frac{n \cdot(1-(n-1) \widetilde{\varphi})^{n-1}-(n-1) \cdot(1-n \widetilde{\varphi})^{n-1}}{n \cdot\left(1-\delta \cdot(1-n \widetilde{\varphi})^{n-1}\right)}=1 .
$$

Finally, if $\widetilde{\varphi}=0, \varphi_{i t}<\widetilde{\varphi}$ cannot occur. Hence, the equilibrium condition boils down to $\widetilde{\varphi} \cdot \Pi+Y \geq \Pi$. Substitution of $\widetilde{\varphi}=0$ and rewriting yields $\delta \geq \frac{n}{n+1}$.

\section{Proof of Corollary 3.4.}

From Theorem 3.3 we already know that for every $\delta \geq \frac{n}{n+1}$ the strategy profile $Q$ is a Bayesian Nash equilibrium for $\widetilde{\varphi}=0$. Consider the function

$$
f(\varphi, \delta)=\delta \cdot \frac{T}{n \cdot\left(1-\delta \cdot(1-n \varphi)^{n-1}\right)}
$$

where $T=n \cdot(1-(n-1) \varphi)^{n-1}-(n-1) \cdot(1-n \varphi)^{n-1}$. From the equilibrium condition in Theorem 3.3 we know that $\varphi>0$ yields a Bayesian Nash equilibrium precisely when $f(\varphi, \delta)=$ $1-\varphi$. We show that this equation has a unique solution on the interior of interval $\left[0, \frac{1}{n}\right]$ precisely when $\delta>\frac{n}{n+1}$.

First note that $f(0, \delta)=\frac{\delta}{n(1-\delta)}$. So, at $\varphi=0$ we have $f(\varphi, \delta)>1-\varphi$ precisely when $\delta>\frac{n}{n+1}$ and $f(\varphi, \delta)=1-\varphi$ precisely when $\delta=\frac{n}{n+1}$. Further, $f\left(\frac{1}{n}, \delta\right)=\delta\left(\frac{1}{n}\right)^{n-1}<1-\frac{1}{n}$. So, at $\varphi=\frac{1}{n}$ we have $f(\varphi, \delta)<1-\frac{1}{n}$. Thus, by the Intermediate Value Theorem, for $\delta \geq \frac{n}{n+1}$ there 
is at least one point of intersection of the respective graphs of $f(\varphi, \delta)$ and $1-\varphi$ on the interval $\left[0, \frac{1}{n}\right]$. Moreover, when $\delta>\frac{n}{n+1}$, the point of intersection is at the interior of the interval $\left[0, \frac{1}{n}\right]$. We show that the point of intersection must be unique in two steps. First we show that $f(\varphi, \delta)<1-\varphi$ on the interval $\left[\frac{1}{n(n-1)}, \frac{1}{n}\right]$. So, there are no points of intersection on the interval $\left[\frac{1}{n(n-1)}, \frac{1}{n}\right]$ and, because $f(0, \delta)>1$, there is at least one point of intersection on the interval $\left(0, \frac{1}{n(n-1)}\right)$. Then we show that $\frac{\partial f}{\partial \varphi}<-1$ on the interval $\left[0, \frac{1}{n(n-1)}\right]$, which establishes the fact that the point of intersection on the interval $\left(0, \frac{1}{n(n-1)}\right)$ is unique. Notice that

$$
\frac{\partial T}{\partial \varphi}=n \cdot(n-1)^{2} \cdot\left((1-n \varphi)^{n-2}-(1-(n-1) \varphi)^{n-2}\right) .
$$

It is easy to check that $\frac{\partial T}{\partial \varphi}<0$.

A. Consider the interval $\left[\frac{1}{n(n-1)}, \frac{1}{n}\right]$. We show that

$$
f(\varphi, \delta)<1-\varphi
$$

on this interval. Using the definition of $f(\varphi, \delta)$, it suffices to show that

$$
T<n \cdot(1-\varphi) \cdot\left(1-\delta \cdot(1-n \varphi)^{n-1}\right) .
$$

Since $\varphi \geq \frac{1}{n(n-1)}$, we know that

$$
\delta \cdot(1-n \varphi)^{n-1}<(1-n \varphi)^{n-1} \leq\left(\frac{n-2}{n-1}\right)^{n-1} .
$$

Thus, since also $\varphi \leq \frac{1}{n}$, it suffices to show that

$$
T \leq n \cdot \frac{n-1}{n} \cdot\left(1-\left(\frac{n-2}{n-1}\right)^{n-1}\right)
$$

or equivalently

$$
T \leq(n-1) \cdot\left(1-\left(\frac{n-2}{n-1}\right)^{n-1}\right) .
$$

Since $\frac{\partial T}{\partial \varphi}<0$ and $\varphi \geq \frac{1}{n(n-1)}$, we can deduce that

$$
T \leq n \cdot\left(\frac{n-1}{n}\right)^{n-1}-(n-1) \cdot\left(\frac{n-2}{n-1}\right)^{n-1} .
$$

Thus, it suffices to check that

$$
n \cdot\left(\frac{n-1}{n}\right)^{n-1}-(n-1) \cdot\left(\frac{n-2}{n-1}\right)^{n-1} \leq(n-1) \cdot\left(1-\left(\frac{n-2}{n-1}\right)^{n-1}\right)
$$

which is equivalent to

$$
n \cdot\left(\frac{n-1}{n}\right)^{n-1} \leq n-1 .
$$


Since $\left(\frac{n}{n-1}\right)^{n-1}$ is increasing in $n$ (monotonically converging to $e$ ), we know that $\left(\frac{n-1}{n}\right)^{n-1} \leq \frac{4}{9}$ for all $n \geq 3$. Hence

$$
n \cdot\left(\frac{n-1}{n}\right)^{n-1} \leq \frac{4}{9} n \leq n-1
$$

for all $n \geq 3$, which concludes the proof of A.

B. We show that $\frac{\partial f}{\partial \varphi}<-1$ on the interval $\left[0, \frac{1}{n(n-1)}\right]$. Notice that

$$
\begin{aligned}
\frac{\partial f}{\partial \varphi} & =\delta \cdot \frac{\frac{\partial T}{\partial \varphi} \cdot n \cdot\left(1-\delta \cdot(1-n \varphi)^{n-1}\right)-\delta \cdot T \cdot n^{2} \cdot(n-1) \cdot(1-n \varphi)^{n-2}}{n^{2} \cdot\left(1-\delta \cdot(1-n \varphi)^{n-1}\right)^{2}} \\
& =\frac{\delta \cdot \frac{\partial T}{\partial \varphi}}{n \cdot\left(1-\delta \cdot(1-n \varphi)^{n-1}\right)}-\frac{\delta^{2} \cdot T \cdot(n-1) \cdot(1-n \varphi)^{n-2}}{\left(1-\delta \cdot(1-n \varphi)^{n-1}\right)^{2}} .
\end{aligned}
$$

Since $\frac{\partial T}{\partial \varphi}<0$, the first term of this expression is negative. We show that

$$
\frac{\delta^{2} \cdot T \cdot(n-1) \cdot(1-n \varphi)^{n-2}}{\left(1-\delta \cdot(1-n \varphi)^{n-1}\right)^{2}} \geq 1
$$

which is equivalent to

$$
\delta^{2} \cdot T \cdot(n-1) \cdot(1-n \varphi)^{n-2} \geq\left(1-\delta \cdot(1-n \varphi)^{n-1}\right)^{2} .
$$

Since $\delta \geq \frac{n}{n+1}, \varphi \leq \frac{1}{n(n-1)}$, and $T$ is a decreasing function, it suffices to show that

$$
\begin{aligned}
\left(\frac{n}{n+1}\right)^{2} \cdot(n-1) \cdot\left(\frac{n-2}{n-1}\right)^{n-2} & \cdot\left(n \cdot\left(\frac{n-1}{n}\right)^{n-1}-(n-1) \cdot\left(\frac{n-2}{n-1}\right)^{n-1}\right) \\
\geq & \left(1-\frac{n}{n+1} \cdot\left(\frac{n-2}{n-1}\right)^{n-1}\right)^{2}
\end{aligned}
$$

which is equivalent to

$$
\begin{aligned}
\left(\frac{n}{n+1}\right)^{2} \cdot(n-1) \cdot\left(\frac{n-1}{n-2}\right) & \cdot\left(n \cdot\left(\frac{n-2}{n}\right)^{n-1}-(n-1) \cdot\left(\frac{n-2}{n-1}\right)^{2(n-1)}\right) \\
\geq & \left(1-\frac{n}{n+1} \cdot\left(\frac{n-2}{n-1}\right)^{n-1}\right)^{2} .
\end{aligned}
$$

Since $\frac{n-2}{n} \geq\left(\frac{n-2}{n-1}\right)^{2}$, we have

$$
n \cdot\left(\frac{n-2}{n}\right)^{n-1}-(n-1) \cdot\left(\frac{n-2}{n-1}\right)^{2(n-1)} \geq\left(\frac{n-2}{n-1}\right)^{2(n-1)} .
$$

Thus, it suffices to show that

$$
\left(\frac{n}{n+1}\right)^{2} \cdot(n-1) \cdot\left(\frac{n-1}{n-2}\right) \cdot\left(\frac{n-2}{n-1}\right)^{2(n-1)} \geq\left(1-\frac{n}{n+1} \cdot\left(\frac{n-2}{n-1}\right)^{n-1}\right)^{2}
$$


which can be rewritten to

$$
n^{2} \cdot(n-1)^{2} \geq(n-2) \cdot\left((n+1) \cdot\left(\frac{n-1}{n-2}\right)^{n-1}-n\right)^{2}
$$

Now, since $\left(\frac{n-1}{n-2}\right)^{n-1} \uparrow e$ as $n \rightarrow \infty$, it suffices to show that

$$
n^{2} \cdot(n-1)^{2} \geq(n-2) \cdot((e-1) \cdot n+e)^{2}
$$

It is straightforward to verify that this inequality holds for all $n \geq 5$. Since the inequality $(*)$ also holds for $n=4$, the only remaining case is $n=3$. For this case we directly compute that on the interval on the interval $\left[0, \frac{1}{3}\right]$ the equation $f(\delta, \varphi)=1-\varphi$ has a unique solution $\varphi^{*}$, and that $\varphi^{*} \leq \frac{1}{6}$.

The equation $f(\varphi, \delta)=1-\varphi$ can be rewritten to $g(\varphi, \delta)=0$ with

$$
g(\varphi, \delta)=27 \delta \varphi^{3}-39 \delta \varphi^{2}+(21 \delta-3) \varphi+3-4 \delta
$$

Thus $\frac{\partial g}{\partial \varphi}=81 \delta \varphi^{2}-78 \delta \varphi+21 \delta-3$, which for $\delta>\frac{3}{4}$ is a strictly positive function on the interval $\left[0, \frac{1}{3}\right]$. So, for $\delta>\frac{3}{4}, g(\varphi, \delta)$ is strictly increasing in $\varphi$ on the interval $\left[0, \frac{1}{3}\right]$. This implies that the equation $g(\varphi, \delta)=0$ has at most one solution on the interval $\left[0, \frac{1}{3}\right]$. It is moreover straightforward to check that $g(0, \delta)=3-4 \delta<0$. Hence, by A, the equation has a unique solution $\varphi^{*}<\frac{1}{6}$. 


\section{References}

[1] Athey S, Bagwell K, Sanchirico C (2004) Collusion and price rigidity. The Review of Economic Studies 71:317-349

[2] Bagwell K, Staiger RW (1997) Collusion over the business cycle. The RAND Journal of Economics 28:82-106

[3] Busse M (2002) Firm Financial Condition and Airline Price Wars. RAND Journal of Economics 33: 298-318

[4] Ellison G (1994) Theories of cartel stability and the Joint Executive Committee. The RAND Journal of Economics 25:37-57

[5] Friedman JW (1971) A non-cooperative equilibrium for supergames. Review of Economic Studies 38:1-12

[6] Green EJ, Porter RH (1984) Noncooperative collusion under imperfect price competition. Econometrica 52:87-100

[7] Guiltinan JP, Gundlach GT (1996) Aggressive and predatory pricing: a framework for analysis. The Journal of Marketing 60:87-102

[8] Haltiwanger J, Harrington Jr. JE (1991) The impact of cyclical demand movements on collusive behavior. The RAND Journal of Economics 22:89-106

[9] Heil OP, Helsen K (2001) Toward an understanding of price wars: their nature and how they erupt. International Journal of Research in Marketing 18:83-98

[10] Kandori M (1991) Correlated demand shocks and price wars during booms. The Review of Economic Studies 58:171-180

[11] Poitevin M (1989) Financial signalling and the "deep pocket argument". RAND Journal of Economics 20:26-40

[12] Pot E, Flesch J, Peeters R, Vermeulen D (2009) Dynamic competition with consumer inertia. METEOR Research Memorandum 09/037 Maastricht University

[13] Pot E, Peeters R, Peters H, Vermeulen D (2009) The determinants of collusion under exogenous demand fluctuations. Mimeo Maastricht University 2009. 
[14] Rao AR, Bergen ME, Davis S (2000) How to fight a price war. Harvard Business Review 78 (March-April):107-116

[15] Rotemberg JJ, Saloner G (1986) A supergame-theoretic model of price wars during booms. American Economic Review 76:390-407

[16] Staiger RW, Wolak FA (1992) Collusive pricing with capacity constraints in the presence of demand uncertainty. The RAND Journal of Economics 23:203-220 